Fetal Diagnosis and Therapy
Fetal Diagn Ther 2012;32:288-291

DOI: $\underline{10.1159 / 000336666}$
Received: November 6, 2011

Accepted after revision: January 17, 2012

Published online: March 21, 2012

\title{
Limb Constriction Secondary to Pseudoamniotic Band Syndrome after Selective Fetoscopic Laser Surgery: Report of a Case with a Favorable Outcome
}

\author{
Andreia Rodrigues Cláudia Araújo Rui Carvalho Maria Antonieta Melo \\ Luísa Pinto Luís Mendes da Graça \\ Department of Obstetrics, Gynecology and Reproductive Medicine, Hospital de Santa Maria, Lisbon, Portugal
}

\section{Established Facts}

- Twin-to-twin transfusion syndrome is a serious complication of monozygotic twins with monochorionic placentation.

- Few studies have addressed the issue of complications related to selective fetoscopic laser photocoagulation in twin-to-twin transfusion syndrome pregnancies.

- There are little or no data on the incidence of pseudoamniotic band syndrome.

\section{Novel Insights}

- In our report the surviving twin had surgical correction with excellent cosmetic and functional results presenting no major postnatal sequelae of PABS.

\section{Key Words}

Limb constriction - Pseudoamniotic band syndrome •

Fetoscopic laser surgery • Twin-to-twin transfusion syndrome

\section{Abstract \\ Pseudoamniotic band syndrome (PABS) is an iatrogenic complication that causes entanglement of fetal parts in a constrictive sheet of detached or ruptured amniotic mem- brane after an invasive procedure, namely amniocentesis, amnioreduction or septostomy in twins. The incidence and}

risk factors for PABS after fetoscopy-guided laser have not been documented [Winer et al.: Am J Obstet Gynecol 2008;198:393.e1-393.e5]. We report a case of monochorionic biamniotic twin pregnancy submitted to selective fetoscopic laser photocoagulation for twin-to-twin transfusion syndrome at 16 weeks of gestation. The procedure was complicated by the death of one of the fetuses at 24 weeks of gestation. Moreover, the surviving twin was diagnosed postnatally with pseudoamniotic band syndrome, presenting with affected limbs. The newborn was submitted to surgical correction of these lesions with a successful outcome and was discharged on day 15.

\section{KARGER}

Fax +4161306 1234

E-Mail karger@karger.ch

www.karger.com (c) 2012 S. Karger AG, Basel

$1015-3837 / 12 / 0324-0288 \$ 38.00 / 0$

Accessible online at: www.karger.com/fdt
Andreia Rodrigues

Department of Obstetrics, Gynecology and Reproductive Medicine

Hospital de Santa Maria, Avenida Egas Moniz

PT-1649-035 Lisbon (Portugal)

Tel. +351919433534, E-Mail andreia.dalmeida@gmail.com 


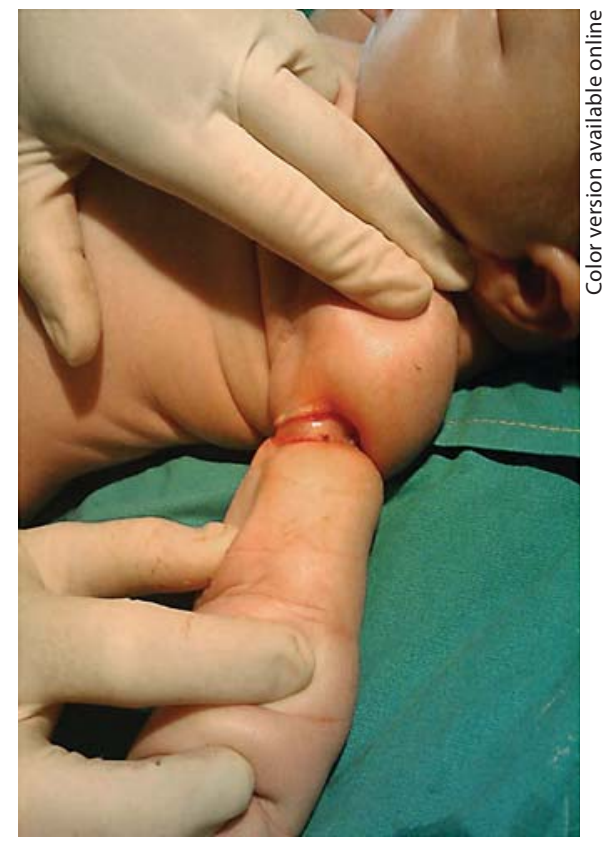

Fig. 1. Constriction ring on the upper left arm.

\section{Case Report}

A 32-year-old Caucasian woman, gravida 1, was referred to our Maternal-Fetal Unit at 9 weeks of gestation for spontaneous monochorionic biamniotic twin pregnancy.

At 12 weeks of gestation, the twins presented concordant crown-rump lengths and amniotic fluid indexes, with nuchal translucencies of 2.3 and $0.8 \mathrm{~mm}$.

An ultrasound examination performed at 16 weeks of gestation revealed Quintero stage II twin-to-twin transfusion syndrome (TTTS). The parents were informed of the risks of TTTS and decided to submit to selective fetoscopic laser photocoagulation (SFLP) of vascular anastomosis. The procedure took place at 16 weeks and 3 days of gestation, at Hospital Clinic in Barcelona, and no immediate complications were noticed. At 17 weeks and 6 days, both twins were alive with concordant amniotic fluid indexes, visible bladders and umbilical artery pulsatility index on the recipient of 2.49 with absent diastolic waves, and on the donor of 1.68. However, at 24 weeks of gestation, demise of the recipient twin was diagnosed. Subsequent scans showed normal growth and activity of the surviving fetus, and pregnancy was otherwise uneventful.

At 39 weeks and 5 days of gestation, a cesarean section for cephalopelvic disproportion was performed, and a 3,910-gram boy was delivered with Apgar scores at the 1st and 5th minutes of 9 and 10, respectively. Physical examination showed a constriction ring on the upper left arm with edema of the distal limb, which was not necrotic (fig. 1), and multiple constriction rings involving the digits of both feet, with amputation of the distal phalange of the second digit of the right foot (fig. 2). Pathological examination of the placenta and amnion confirmed the diagno-

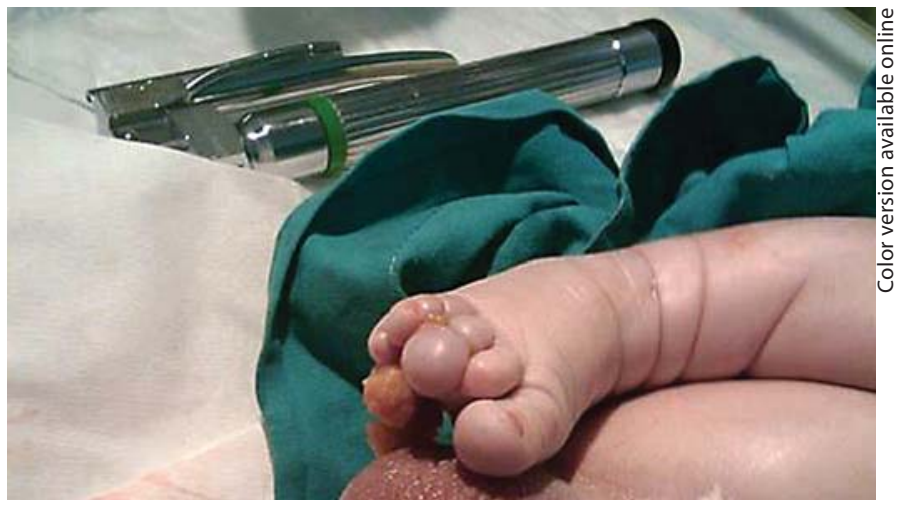

Fig. 2. Digits of both feet with multiple constriction rings, with secondary amputation of the distal phalange of the second digit of the right foot.

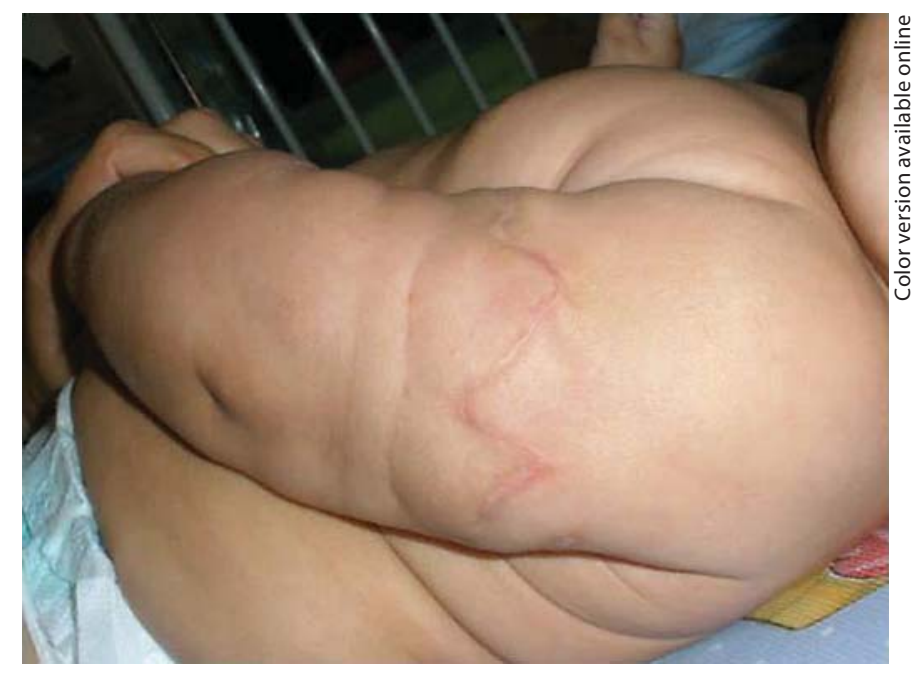

Fig. 3. Operated upper left arm on the 8th day of life.

sis of pseudoamniotic band syndrome (PABS). The placenta was morphologically compatible with gestational age. It presented significant villous sclerosis, perivillous fibrin deposition and microcalcifications, with maceration and mummification of the umbilical cord and amniotic membrane of the demised fetus, secondary to his death. The remaining placenta had no anomalies, except for chorioamnionitis and vasculitis of umbilical cord of the surviving twin. The pathology of the demised fetus, although limited by advanced state of mummification, showed no malformations and biometry was compatible with 18 weeks of gestation.

A web reconstruction of the upper left arm was performed via Z-plasty on the 8th day of life. The newborn was discharged on day 15. Functional recovery of the left arm and hand was confirmed after 1 month of follow-up (fig. 3). 


\section{Discussion}

TTTS is a serious complication of monozygotic twin gestations, with an incidence that ranges from 10 to $15 \%$ of the monochorionic biamniotic gestations [2]. It is defined sonographically by the combined presence of polyhydramnios in one sac and oligohydramnios in the other [3]. Intertwin placental anastomoses are the basis for the onset of TTTS. Although intertwin transfusion is a constant and usually balanced phenomenon in monochorionic twins, a chronic imbalance in net flow can trigger TTTS [4].

TTTS is one of the most lethal perinatal complications, with an $80-100 \%$ mortality rate and a $15-50 \%$ risk of disability in survivors without treatment [5].

Therapeutic interventions in this disorder are all invasive, with success rates related to gestational age at diagnosis and treatment, severity of the disease at the time of treatment and type of intervention. These procedures include amnioreduction, septostomy, laser photocoagulation of the placental anastomoses, and umbilical cord occlusion by bipolar diathermy [6].

In the Eurofoetus randomized controlled trial, SFLP of the chorionic vessels was considered a more effective first-line treatment than serial amniodrainage in severe TTTS diagnosed before 26 weeks of gestation. SFLP was shown to result in at least one survivor at birth and intact survival at 6 months of age in 76 and $56 \%$ of the cases, respectively, as compared with 56 and $51 \%$, respectively, in cases treated by aminodrainage [7]. Salomon et al. [8] prospectively studied the neurologic and neurodevelopmental outcomes up to the age of 6 years in infants included in the Eurofoetus trial, and concluded that SFLP therapy is associated with an almost $40 \%$ reduction in the risk of fetal death or long-term major neurological impairment and that infants treated in the SLFP group had higher ASQ scores at the age of 5 years (60 months).

Few studies have addressed the issue of complications related to SFLP in TTTS pregnancies. According to a recent review by Beck et al. [9], iatrogenic preterm prelabor rupture of membranes remains the most important complication of minimally invasive fetal procedures. Some techniques like amniopatch [10] have been attempted to reduce the rate of complications, with variable results. Little or no data are presented on the incidence of PABS, where there is entanglement of fetal parts in a constrictive sheet of detached or ruptured amniotic membrane after invasive procedures such as amniocentesis [11-13], amnioreduction [14], or septostomy in twins [15]. In a smaller retrospective study by Habli et al. [16] involving 152 patients with TTTS who were treated with SFLP at 16-26 weeks of gestation, 5 cases (3.3\%) had PABS. Winer et al. [1] in a prospective study of 438 consecutive TTTS cases treated at 15-26 weeks of gestation reported PABS in 8 cases (1.8\%). All the cases described by Winer survived the perinatal period and the affected twin was always the former recipient. In our case the recipient was demised at 24 weeks of gestation and the donor presented sequels of PABS. As the procedure was reported without immediate complications, we can only speculate on a nondiagnosed intertwin membrane rupture or detachment, since during the delivery we did not identify any amniotic membrane between both fetuses. Inadvertent septostomy has been reported to occur in $7 \%$ of cases after fetoscopic laser therapy, and is associated with an increased risk of adverse perinatal outcome and PABS [17]. The diagnosis of PABS was made prenatally in only 2 of 8 cases (25\%) [1], highlighting the poor sensitivity of prenatal diagnosis for this condition. In our case, ultrasonographic diagnosis of the situation could not be made prenatally as the abnormalities were subtle.

Though a rare condition, we should be aware of the possibility of PABS in pregnancies that are treated by SFLP for TTTS, especially when fetal death of one twin occurs. In our report, the surviving twin had surgical correction with excellent cosmetic and functional results presenting no major postnatal sequelae of PABS. Nonetheless, some authors suggest the use of targeted ultrasound follow-up examination with Doppler studies and three-dimensional sonography $[18,19]$ because this may contribute to better diagnosis, counseling, treatment and long-term outcome of cases that are complicated with PABS.

References

$D_{1}$ Winer N, Salomon LJ, Essaoui M, Nasr B, Bernard JP, Vile Y: Pseudoamniotic band syndrome: a rare complication of monochorionic twins with fetofetal transfusion syndrome treated by laser coagulation. Am J Obstet Gynecol 2008;198:393.e1-393.e5.

2 Harkness UF, Crombleholme TM: Twintwin transfusion syndrome: where do we go from here? Semin Perinatol 2005;29:296304.

3 Quintero RA: Twin-twin transfusion syndrome. Clin Perinatol 2003;30:591-600.

4 El Kateb A, Ville Y: Update on twin-to-twin transfusion syndrome. Best Pract Res Clin Obstet Gynaecol 2008;22:63-75. 
5 Yamamoto M, El Murr L, Robyr R, et al: Incidence and impact of peri-operative complications in 175 fetoscopy-guided laser coagulations of chorionic plate anastomoses in fetofetal transfusion syndrome before 26 weeks of gestation. Am J Obstet Gynecol 2005;193:1110-1116.

-6 Trevett T, Johnson A: Monochorionic twin pregnancies. Clin Perinatol 2005;32:475494.

7 Senat MV, Deprest J, Boulvain M, et al: Endoscopic laser surgery versus serial amnioreduction for severe twin-to-twin transfusion syndrome. N Engl J Med 2004;351:136-144.

$\checkmark 8$ Salomon LJ, Örtqvist L, Aegerter P, et al: Long-term developmental follow-up of infants who participated in a randomized clinical trial of amniocentesis vs. laser photocoagulation for the treatment of twin-to-twin transfusion syndrome. Am J Obstet Gynecol 2010;203:444.
9 Beck V, Lewi P, Gucciardo L, Devlieger R: Preterm prelabor rupture of membranes and fetal survival after minimally invasive fetal surgery: a systematic review of the literature. Fetal Diagn Ther 2011 Nov 19. [Epub ahead of print].

10 Pathak B, Khan A, Assaf SA, Miller DA, Chmait RH: Amniopatch as a treatment for rupture of membranes following laser surgery for twin-twin transfusion syndrome. Fetal Diagn Ther 2010;27:134-137.

11 Moessinger AC, Blanc WA, Byrne J, Andrews D, Warburton D, Bloom A: Amniotic band syndrome associated with amniocentesis. Am J Obstet Gynecol 1981;141:588591.

12 Kohn G: The amniotic band syndrome: a possible complication of amniocentesis. Prenat Diagn 1987;7:303-305.

13 Strauss A, Hasbargen U, Paek B, Bauerfeind I, Hepp H: Intra-uterine fetal demise caused by amniotic band syndrome after standard amniocentesis. Fetal Diagn Ther 2000;15: $4-7$.

14 Von Eckardstein S, Reihs T, Crombach G: Constriction of an extremity after amnioreduction in a TRAP-like sequence. Fetal Diagn Ther 1997;12:50-53.

15 Cook TL, O’Shaughnessy R: Iatrogenic creation of a monoamniotic twin gestation in severe twin-twin transfusion syndrome. J Ultrasound Med 1997;16:853-855.
6 Habli M, Bombrys A, Lewis D, et al: Incidence of complications in twin-twin transfusion syndrome after selective fetoscopic laser photocoagulation: a single-center experience. Am J Obstet Gynecol 2009;201:417.

17 Cruz-Martinez R, Van Mieghem T, Lewi L, Eixarch E, Cobo T, Martinez JM, Deprest J, Gratacos E: Incidence and clinical implications of early inadvertent septostomy after laser therapy for twin-twin transfusion syndrome. Ultrasound Obstet Gynecol 2011;37: 458-462.

18 Paladini D, Foglia S, Sglavo G, Martinelli P: Congenital constriction band of the upper arm: the role of three-dimensional ultrasound in diagnosis, counseling and multidisciplinary consultation. Ultrasound $\mathrm{Ob}$ stet Gynecol 2004;23:520-522.

19 Sentilhes L, Verspyck E, Eurin D, et al: Favourable outcome of a tight constriction band secondary to amniotic band syndrome. Prenat Diagn 2004;24:198-201. 